\title{
EARLY DECOMPRESSION FOLLOWING CERVICAL SPINAL CORD \\ INJURY: EXAMINING THE PROCESS OF CARE FROM ACCIDENT SCENE \\ TO SURGERY.
}

Camila R. Battistuzzo, PhD, Department of Medicine (Royal Melbourne Hospital), The University of Melbourne, Royal Parade, Parkville, Melbourne, VIC, 3050, Australia (Ph: +61 38344 6252, Fax: +61 39347 1863, email: camilab@unimelb.edu.au).

Alex Armstrong, MBBS, School of Animal Biology, The University of Western Australia, 35 Stirling Highway, Perth, WA, 6009, Australia (Ph: +61 86488 2228, Fax: +61 86488 1029, email: 20917619@student.uwa.edu.au).

Jillian Clark, PhD, Centre for Orthopaedic and Trauma Research, Faculty of Health Sciences, The University of Adelaide, North Terrace, Adelaide, SA, 5000, Australia (Ph: +61 882122 1651, Fax: +61 88222 1644, email: Jillian.Clark@health.sa.gov.au).

Laura Worley, BOccThy, Queensland Spinal Injuries Service, Princess Alexandra Hospital, Ispwich Rd, Woolloongabba, QLD, 4102, Australia (Ph: +61 73676 5117, Fax: +61 73176 5061, email: Laura.Worley@health.qld.gov.au).

Lisa Sharwood, PhD, John Walsh Centre for Rehabilitation Research, The University of Sydney, Reserve Rd, Sydney, NSW, 2065 Australia (Ph: +61 4 0983 8096, Fax: +61 2935 222, email: lisa.sharwood@sydney.edu.au).

Peny Lin, MBchB, Orthopaedic Department, Middlemore Hospital, 100 Hospital Rd, Auckland, 2025, New Zealand (Ph: +64 9277 1660, Fax: +64 9 277 1600, email: peny.lin@gmail.com).

Gareth Rooke, MASurg, Orthopaedic Department, Christchurch Hospital, Riccarton Avenue, Christchurch, 8140, New Zealand (Ph: +64 3364 0800, Fax: +64 3364 0806, email: gmjrooke@hotmail.com).

Peta Skeers, Bsc(Hons), Department of Medicine (Royal Melbourne Hospital), The University of Melbourne, Royal Parade, Parkville, Melbourne, VIC, 3050, 
Australia (Ph: +61 38344 6252, Fax: +61 39347 1863, email: peta.skeers@unimelb.edu.au).

Sherilyn Nolan, BPhty, School of Animal Biology, The University of Western Australia, 35 Stirling Highway, Perth, WA, 6009, Australia (Ph: +61 86488 2228, Fax: +61 86488 1029, email: sherilyn.nolan@health.wa.gov.au).

Timothy Geraghty, MBBS, Queensland Spinal Injuries Service, Princess Alexandra Hospital, Ispwich Rd, Woolloongabba, QLD, 4102, Australia (Ph: +61 73676 5117, Fax: +61 73176 5061, email: Timothy.Geraghty@health.qld.gov.au)

Andrew Nunn, MBBS, Victorian Spinal Cord Service, Austin Hospital, 140 Studley Rd, Heidelberg, Melbourne, VIC, 3084, Australia (Ph: +61 39496 5220, Fax: +61 39458 4779, email: Andrew.nunn@austin.org.au).

Doug J Brown, MBBS, The Spinal Research Institute, 1 Yarra Boulevard, Kew, Melbourne, VIC, 3101, Australia (Ph: +61 39490 7500, Fax: +61 39458 4779, email: doug.brown@thesri.org).

Stephen Hill, MBBS, Victorian Spinal Cord Service, Austin Hospital, 140 Studley Rd, Heidelberg, Melbourne, VIC, 3084, Australia (Ph: +61 39496 5220, Fax: +61 39458 4779, email: steven.hill@austin.org.au).

Janette Alexander, BPhty, Victorian Spinal Cord Service, Austin Hospital, 140 Studley Rd, Heidelberg, Melbourne, VIC, 3084, Australia (Ph: +61 39496 5220, Fax: +61 39458 4779, email: janette.alexander@austin.org.au).

Melinda Millard, BAppSC(Nsg), Victorian Spinal Cord Service, Austin Hospital, 140 Studley Rd, Heidelberg, Melbourne, VIC, 3084, Australia (Ph: +61 39496 5220, Fax: +61 39458 4779, email: melinda.millard@austin.org.au).

Susan F. Cox, MSc, Neuroscience Trials Australia, The Florey Institute of Neuroscience, 245 Burgundy St, Heidelberg, Melbourne, VIC, 3084, Australia (Ph: +61 39035 7233, Fax: +61 39496 2881, email: sfc@unimelb.edu.au).

Sudhakar Rao, MBBS, Trauma Service, Royal Perth Hospital, 197 Wellington St, Perth, WA, 6000, Australia (Ph: +61 89224 2551, Fax: +61 892243511 , email: sudhakar.rao@health.wa.gov.au). 
Ann Watts, BAppSC(Nsg), Spinal Unit, Royal Perth Hospital, 197 Wellington St, Perth, WA, 6000, Australia (Ph: +61 89224 2551, Fax: +61 892243511 , email:ann.watts@health.wa.gov.au).

Louise Goods, BPhty, School of Animal Biology, The University of Western Australia, 35 Stirling Highway, Perth, WA, 6009, Australia (Ph: +61 86488 2228, Fax: +61 86488 1029, email: louise.goodes@uwa.edu.au).

Gary T. Allison, PhD, School of Physiotherapy and Exercise Science, Faculty of Health Sciences, Curtin University, Kent St, Bentley, WA, 6102, Australia (Ph: +61 89226 2993, Fax: +61 89226 2608, email: G.Allison@curtin.edu.au).

Jacqui Laurenson, BPhty, Department of Medicine (Royal Melbourne Hospital), The University of Melbourne, Royal Parade, Parkville, Melbourne, VIC, 3050, Australia (Ph: +61 38344 6252, Fax: +61 39347 1863, email: jlaurenson@student.unimelb.edu.au).

Peter A. Cameron, MD, Emergency and Trauma Centre, The Alfred Hospital, 55 Commercial Rd, Melbourne, VIC, 3004, Australia (Ph: +61 39076 5325, Fax: +61 39076 5319, email: peter.cameron@monash.edu).

Ian Mosley, PhD, College of Science, Health and Engineering, La Trobe University, Plenty Rd, Melbourne, VIC, 3086, Australia (Ph: +61 39479 5935, Fax:+61 39479 1464, email: I.Mosley@latrobe.edu.au).

Susan M. Liew, MBBS, Department of Orthopaedic Surgery, The Alfred Hospital, 55 Commercial Rd, Melbourne, VIC, 3004, Australia (Ph: +61 3 9076 2025, Fax: +61 39076 6938, email: s.liew@alfred.org.au).

Tom Geddes, MBchB, Orthopaedic Department, Middlemore Hospital, 100 Hospital Rd, Auckland, 2025, New Zealand (Ph: +64 9277 1660, Fax: +64 9 277 1600, email: tom.geddes@middlemore.co.nz).

James Middleton, PhD, John Walsh Centre for Rehabilitation Research, The University of Sydney, Reserve Rd, Sydney, NSW, 2065 Australia (Ph: +61 4 0983 8096, Fax: +61 2935 222, email: james.middleton@sydney.edu.au). 
John Buchanan, PhD, Department of Physiotherapy, Royal Perth Hospital, 197 Wellington St, Perth, WA, 6000, Australia (Ph: +61 89224 2076, Fax: +61 89224 3007, email: John.Buchanan@health.wa.gov.au).

Jeffrey V. Rosenfeld, MD, Department of Neurosurgery, The Alfred Hospital, 55 Commercial Rd, Melbourne, VIC, 3004, Australia (Ph: +61 39076 2025, Fax: +61 39076 6067, email: J.Rosenfeld@alfred.org.au).

Stephen Bernard, PhD, Intensive Care Unit, The Alfred Hospital, 55 Commercial Rd, Melbourne, VIC, 3004, Australia (Ph: +61 39076 3036, Fax: +6139076 3780, email: S.Bernard@alfred.org.au).

Sridhar Atresh, MBBS, Queensland Spinal Injuries Service, Princess Alexandra Hospital, Ispwich Rd, Woolloongabba, QLD, 4102, Australia (Ph: +61 73676 5117, Fax: +61 $7 \quad 3176$ 5061, email: Sridhar.Atresh@health.qld.gov.au)

Alpesh Patel, MBchB, Orthopaedic Department, Middlemore Hospital, 100 Hospital Rd, Auckland, 2025, New Zealand (Ph: +64 9277 1660, Fax: +64 9 277 1600, email: aucpatel@hotmail.com)

Rowan Schouten, MBchB, Orthopaedic Department, Christchurch Hospital, Riccarton Avenue, Christchurch, 8140, New Zealand (Ph: +64 33640800 , Fax: +64 3364 0806, email: rowanschouten@gmail.com).

Brian J.C. Freeman, MD, Spinal Injuries Unit, Department of Orthopaedics and Trauma, Royal Adelaide Hospital, The University of Adelaide, North Terrace, Adelaide, SA, 5000, Australia (Ph: +61 88222 4466, Fax: +61 8 8222 2480, email: brian.freeman@health.sa.gov.au).

Sarah A. Dunlop, PhD, School of Animal Biology, The University of Western Australia, 35 Stirling Highway, Perth, WA, 6009, Australia (Ph: +61 86488 2228, Fax: +61 86488 1029, email: sarah.dunlop@uwa.edu.au)

Peter E. Batchelor*, PhD, Department of Medicine (Royal Melbourne Hospital), The University of Melbourne, Royal Parade, Parkville, Melbourne, VIC, 3050, Australia (Ph: +61 38344 6252, Fax: +61 39347 1863, email: batch@bigpond.net.au). 
* Corresponding author: Peter E Batchelor, Department of Medicine (Royal Melbourne Hospital), The University of Melbourne, Royal Parade, Parkville, Melbourne, VIC, 3050, Australia (Ph: +61 38344 6252, Fax: +61 39347 1863, email: batch@bigpond.net.au).

Running title: Process of care from accident scene to surgery.

Table of Contents title: Process of care from accident scene to surgery following spinal cord injury. 
ABSTRACT

Early decompression may improve neurological outcome after spinal cord injury (SCI), but is often difficult to achieve because of logistical issues. The aims of this study were to determine (1) the time to decompression in cases of isolated cervical SCI in Australia and New Zealand and (2) where substantial delays occur as patients move from the accident scene to surgery. Data were extracted from medical records of patients aged 15-70 years with C3-T1 traumatic SCI between 2010 and 2013. A total of 192 patients were included. The median time from accident scene to decompression was $21 \mathrm{~h}$, with the fastest times associated with closed reduction (6h). A significant decrease in the time to decompression occurred from 2010 (31h) to 2013 (19h, $p=0.008)$. Patients undergoing direct surgical hospital admission had a significantly lower time to decompression compared to patients undergoing pre-surgical hospital admission (12h vs. 26h, $p<0.0001$ ). Medical stabilisation and radiological investigation appeared not to influence the timing of surgery. The time taken to organise theatre following surgical hospital admission was a further factor delaying decompression (12.5h). There was a relationship between the timing of decompression and the proportion of patients demonstrating substantial recovery (2-3 AIS grades). In conclusion, the time of cervical spine decompression markedly improved over the study period. Neurological recovery appeared to be promoted by rapid decompression. Direct surgical hospital admission, rapid organisation of theatre and where possible use of closed reduction, are likely to be effective strategies to reduce the time to decompression. 
Key words: spinal cord injury, spine surgery, process of care, decompression. 


\section{INTRODUCTION}

Acute traumatic spinal cord injury (SCI) generally affects young people and most have severe paralysis and functional deficits with ongoing complex social, psychological and medical needs. ${ }^{1,2} \mathrm{~A}$ therapy with emerging evidence of benefit is early decompression, whereby persisting pressure on the spinal cord from fractures, dislocations and associated vertebral trauma, is promptly corrected. $^{3,4}$

Pre-clinical data examining early decompression consistently demonstrate improved outcomes, albeit in models not always consistent with the nature and time course of human injury. ${ }^{5}$ Clinical studies of cervical SCI suggest that early decompression within 24 hours of injury improves neurological function in a small proportion of patients, ${ }^{6-10}$ with decompression not appearing to influence neurological recovery when performed beyond this time..$^{11-16}$ The proportion and magnitude of benefit may increase as the time to surgery shortens, consistent with animal studies. ${ }^{7,17}$ Early surgery also appears to reduce complications and shorten hospital length of stay. ${ }^{6,7,18,19}$ However, performing early decompression is often challenging because of the time occupied by the complicated process of care from accident scene to surgery. Delays can occur at many stages including paramedic retrieval and transportation, pre-surgical hospital admission, surgical hospital assessment, medical stabilisation, investigation and operating theatre access. To minimise the time to early decompression, it is crucial to understand and determine the duration of each step in the process of care from accident scene through to surgery. This allows substantial delays to be identified and focused solutions 
can then be developed to reduce these delays. The aims of this study were (1) to determine the median time to decompression in cases of isolated cervical SCl over a period of four years in Australia and New Zealand and (2) to determine where substantial delays occur as patients move from the accident scene to surgery.

\section{METHODS}

\section{Study design and ethical approval}

A retrospective analysis of cases with isolated cervical $\mathrm{SCl}$ that underwent decompression over a four year period (2010 to 2013) was conducted within Australia and New Zealand. The following hospitals were involved in this study: Austin Hospital (Melbourne, VIC, Australia), The Alfred Hospital (Melbourne, VIC, Australia), Royal Adelaide Hospital (Adelaide, SA, Australia), Royal Perth Hospital (Perth, WA, Australia), Princess Alexandra Hospital (Brisbane, QLD, Australia), Royal North Shore Hospital (Sydney, NWS, Australia), Prince of Wales (Sydney, NWS, Australia), Middlemore Hospital (Auckland, New Zealand) and Christchurch Hospital (Christchurch, New Zealand). A list of all traumatic cervical SCI admission cases was obtained from each hospital for the defined data collection period. All relevant Human Research Ethics Committees were advised of the project and Data Audit or Low-risk Human Research Ethical Approvals were obtained where required at each institution.

Inclusion and exclusion criteria 
Patients between 15 and 70 years with a C3-T1 fracture, fracture-dislocation, disc and/or ligamentous injury in association with an acute traumatic SCI with neurological deficits were included in the study. Spinal decompression was achieved either by closed or open reduction. Patients were excluded from the study if the time of injury and time of spinal decompression were not available.

Patients with multiple traumatic injuries (defined as trauma to at least one other major organ, significant abdominal bleeding or retro-peritoneal haemorrhage likely to require intervention, pelvic fracture likely to require intervention, more than two long bone fractures requiring operative fixation), ISS (Injury Severity Score) > 16, significant head injury defined by sustained GCS (Glasgow Coma Scale) < 13 at the scene and penetrating SCI (not involving decompression surgery) were excluded from the study. Patients with traumatic central cord syndrome (TCCS) were excluded as the urgency of treatment for these patients varied across institutions. In addition, patients with pre-existent major neurological deficits or disease (e.g. stroke, Parkinson's disease) were excluded.

\section{Data collection and management}

A data dictionary was created to ensure standardised data collection across sites. All data was entered as a de-identifiable format using a Research Electronic Data Capture (REDCap), a secure (username and password protected) web-based database hosted by the Florey Institute of Neuroscience and Mental Health. ${ }^{20}$

For each included case, the following data fields were collected: demographics (date of birth and gender), injury event (date and time of injury, 
location of accident, cause of accident, initial GCS), metropolitan, rural and remote accident location (based on the population size and distance to the nearest urban centre), ambulance (date and time paramedic call was received, date and time ambulance arrived at patient, transporting ambulance departure date and time, date and time of arrival at first hospital), hospital admission (date and time left first hospital, date and time of arrival at surgical hospital, date and time of spinal computed tomography (CT) scan, date and time of spinal magnetic resonance imaging scan (MRI). In addition injury characteristics (level and type of spinal fracture, level of neurological deficit, extent of lesion and American Spinal Injury Association Impairment Scale (AIS) grade at surgical hospital admission and at rehabilitation discharge) and surgical intervention (type of surgery, date and time of closed reduction, date and time of initiation of decompression surgery defined as the first anaesthetic entry of surgery, date and time of completion of decompression surgery defined as the last anaesthetic entry of surgery).

\section{Data analysis}

On completion of data collection, all data were scrutinised for completeness and accuracy, and then de-identified prior to analysis. The following epochs were calculated for each individual case: time of injury to first ambulance arrival, first ambulance arrival to ambulance departure, ambulance departure to first hospital admission, total paramedic time (time between injury and first hospital admission), pre-surgical hospital time (time between admission at first hospital and admission to the surgical hospital), hospital admission and spinal CT scan, hospital admission and spinal MRI (time of the first spinal CT/MRI 
was used, regardless of at which hospital radiology was performed), surgical hospital admission (time between surgical hospital admission and spinal decompression). Time to spinal decompression was defined as the time of injury to the midpoint between initiation and completion of decompressive surgery. For the purposes of this study, patients were regarded as having undergone closed reduction if the procedure was performed prior to and separate from open cervical spine decompression surgery. ${ }^{17}$ If closed reduction was performed and deemed successful, the time of closed reduction was taken to be the time of spinal decompression. Closed reduction was regarded as successful if the treating spinal or neurosurgical team felt that reduction and realignment were adequate on post-reduction $\mathrm{MRI}$ or $\mathrm{CT}$ imaging. Simple cervical traction was not regarded as attempting urgent closed reduction unless combined with clinical follow-up prior to surgery and post-reduction imaging. Surgical approaches, for patients who underwent decompression surgery, were divided into anterior decompression and stabilisation, posterior decompression and stabilisation or both (anterior and posterior approach). The main data outcomes (total time to decompression and time to decompression by year) were analysed for each site. As the overall process of care followed the same course at all sites, further data were combined for analysis.

\section{Statistical analysis}

Non-parametric data were compared using Mann-Whitney $U$ t-test (two-tailed) and significance was set at $p<0.05$. The Chi-squared test was used to investigate associations between categorical variables, with Fisher's exact 
test employed where the expected frequencies were less than five. Data are presented as median and interquartile range (IQR), unless otherwise stated. Statistical analyses were performed using Prism software (version 6, GraphPad, CA, USA) and Igor Pro 6.0 software (WaveMetrics, Portland, OR). 


\section{Results}

\section{Demographics}

A total of 192 patients met the inclusion criteria and were included in the study. Demographic and injury details are shown in Table 1. The mean age was 36 years \pm 17 (mean \pm SD) and majority of patients (83\%) were male. The majority of SCls (56\%) occurred in a metropolitan area and were commonly a result of high-speed motor vehicle accidents (speed $>60 \mathrm{~km} / \mathrm{h}$ ). High falls (> 1 metre) and water-related accidents (e.g. diving, surfing) were also a common cause of injury. The most frequent neurological level of injury was C5 (30\%). A slightly smaller proportion of patients had a C4 (26\%) or C6 (22\%) neurological of level of injury (Figure 1).

The majority of patients $(76 \%)$, who were treated with surgical decompression, underwent anterior spinal decompression and stabilization. A posterior approach to decompression and stabilization was employed in $12 \%$ of patients, while both approaches were used in a further $12 \%$ of cases.

\section{Timing of spinal decompression}

The median time between accident and spinal decompression (open or closed) throughout Australia and New Zealand was 21 hours (IQR: $12-41$, Figure 2) over the study period. The median time to spinal decompression was similar amongst sites. The IQR, however, varied between sites and, as expected, was larger (because of an increase in the upper range) for sites with a more geographically dispersed population (e.g. Queensland and Western Australia). In Victoria $(n=52)$, Western Australia $(n=27)$ and 
Queensland $(n=56)$ the time to spinal decompression respectively was 21 hours (IQR: $11-32)$, 20 hours (IQR: $10-159)$ and 22 hours (IQR: $12-41$ ). South Australia $(n=11)$ and New South Wales $(n=8)$ had slightly lower median times to decompression (14 hours, IQR: $11-26$ and 19 hours, IQR: $14-28$, respectively). Both sites in New Zealand, Christchurch $(n=26)$ and Auckland $(n=12)$ also had similar median time to decompression (29 hours, IQR: $13-49$ and 26 hours, IQR: $14-70$, respectively).

\section{Process of care}

In order to understand the process of care from accident scene to decompression, this period was divided into three broad phases. The initial phase (paramedic time) was the period between time of injury and first hospital admission. This period was remarkably brief, with an overall median time of 1.1 hours (IQR: $0.7-1.5)$. The next phase was admission to a presurgical hospital (time between admission at first hospital and admission to the surgical hospital). The median time for this phase was 8.9 hours (IQR: 5.8 - 16). Admission to pre-surgical hospital before transfer to a spinal surgical hospital occurred in $59 \%$ of cases, while direct transfer following paramedic assessment occurred in $41 \%$ of cases. The final phase was that of surgical hospital admission (time between surgical hospital admission to spinal decompression). This period had the longest median time (12.5 hours, IQR: 7.6 - 21) and encompassed the time taken to complete radiological investigations and organize surgery. The timing of radiology is important, as surgical decisions are commonly based on these investigations. As expected, the median time taken to complete spinal CT scans was significantly shorter 
than the median time to complete spinal MRI (1.2 hours, IQR: $0.7-2.1$ and 4.5 hours, IQR: $2.8-13, p<0.0001)$. However, the time taken to complete radiology was a fraction of the total time from surgical hospital admission to spinal decompression (12.5 hours, IQR: $7.6-21)$.

Improvement in the timing of spinal decompression

The median time to spinal decompression steadily decreased in each of the analysed years (Figure 3A). In $2010(n=44)$ the median time to decompression was 31 hours (IQR: 15.9 - 52.2), decreasing to 22 hours (IQR: $11.2-45.7)$ and 20 hours (IQR: $11.8-42.8)$ in $2011(n=47)$ and 2012 ( $n=51)$ respectively. By $2013(n=50)$ the median time to spinal decompression was significantly lower than 2010 (19 hours, IQR: $11.1-26.7$, $p=0.008)$. The yearly median time to spinal decompression together with a cumulative histogram of the time to decompression for each individual site can be found in Supplement 1.

To identify where improvements occurred over the study period, each of the three phases in 2010 was compared with those from 2013 (Figure 3B). The median time from paramedic arrival to delivery of the patient to hospital was close to one hour in both years ( 0.9 hours and 1.0 hours, respectively). The median duration of pre-surgical hospital admission was also not significantly different between these years (7.7 hours in 2010 and 9.6 hours in 2013). The median time from surgical hospital admission to decompression was the only phase that improved significantly between 2010 and 2013 (17.8 hours and 11.0 hours, respectively, $p=0.02$ ). This did not appear to be a result of faster completion of radiological investigations, as the median time between hospital 
admission and CT and/or MRI scan was similar between 2010 and 2013 (CT: $2010=1.3$ hours and $2013=1.4$ hours and MRI: $2010=5.1$ hours and 2013 $=3.8$ hours). Collectively, these data suggest that the improvement in the process of care observed over the study period resulted mainly in reduced time to the operating theatre.

One important factor contributing to the reduced time to decompression over the study period was an increase in the rate of direct admission to the surgical hospital. The percentage of cases taken directly to a surgical centre demonstrated a gradual increase over the 4 years $(2010=34 \%, 2011=40 \%$, $2012=41 \%$ and $2013=46 \%)$.

Factors associated with early and delayed spinal decompression

The main factor influencing the timing of spinal decompression was whether patients were taken straight from the accident scene to a surgical hospital or via a pre-surgical hospital. The process of care for these two groups of patients is represented in Figure 4. The overall median time to spinal decompression for cases taken via a pre-surgical hospital (26 hours, $n=114$ ) was significantly greater than for cases taken directly to a surgical hospital (12 hours, $p<0.0001 ; \mathrm{n}=78$ ). For patients admitted directly to a surgical hospital, the median paramedic time was 1.1 hours (IQR: $0.8-1.5)$. The median time of the surgical hospital admission phase (time between surgical hospital admission and spinal decompression) was 11 hours (IQR: $7.8-22$ ). Within this phase, spinal CT and MRI were completed in a median time of 1.3 hours (IQR: 0.7 - 2.2) and 4.1 hours (IQR: 3.3 - 13) respectively following admission. 
For cases taken via a pre-surgical hospital, the paramedic time was also brief (1.1 hours, IQR: 0.71 - 1.5). The median time of pre-surgical hospital admission was 8.9 hours and this was consistent over the study period. The median time of surgical hospital admission in this group was 13 hours (IQR: 7.4 - 21). While spinal CT was commonly performed at the pre-surgical hospital ( $90 \%$ of cases), spinal MRI scanning was usually undertaken at the surgical hospital (78\% of cases). The median time between hospital admission and completion of radiology (CT: 1.0 hour, IQR: $0.6-2.0$ and MRI: 4.7 hours, IQR: 2.5 - 12) was similar to that for patients taken straight to a surgical hospital.

Another factor associated with early or delayed spinal decompression was the geographical location of injury. Patients injured in remote areas $(10 \%$ of cases) had a significantly higher median time to decompression compared to patients injured in metropolitan areas (34 hours, IQR: 21 - 51 and 16 hours, IQR: $10-26$, respectively, $p=0.0002$, Figure $5 A$ ).

The final important factor influencing the timing of spinal decompression was the method of reduction. Of the 192 cases included, only $9(5 \%)$ had successful closed reduction of the cervical spine (all performed in New Zealand). The median time to closed reduction was significantly lower compared to the median time to open reduction (6 hours, IQR: $4-11$ vs. 22 hours, IQR: $13-43, p<0.0001$, Figure $5 B)$.

\section{Timing of spinal decompression and neurological change}

The degree of neurologic improvement was measured by the change in AIS grade from acute surgical hospital admission to rehabilitation discharge. From 
165 patients with documentation of the AIS grade data at these two time points, $97(59 \%)$ had no change in the AIS grade, while $45(27 \%)$ and 18 (11\%) cases had an improvement in the AIS by one and two grades, respectively. A three grade (A to D) improvement occurred in only $4(2 \%)$ cases. One case $(0.6 \%)$ changed from AIS B at surgical hospital admission to AIS $A$ at rehabilitation discharge. None of the included patients improved to AIS E.

The median time to spinal decompression of patients that had no change or one grade improvement in the AIS was 24 hours (IQR: $12-45)$ and 22 hours (IQR: 13 -34), respectively. The median time to spinal decompression of patients that improved by AIS 2-3 grades was lower compared to the above patients (15 hours, IQR: 8 - 38). This difference was not significant. In an analysis similar to the STASCIS trial, ${ }^{6}$ we found that $16 \%$ of cases decompressed $\leq 24$ hours improved 2 or 3 AIS grades, whereas the same improvement occurred in $11 \%$ of cases decompressed more than 24 hours after injury. This difference was not also significant. (Chi-squared test, $p=$ 0.35).

A relationship between the time of spinal decompression and the proportion of patients improving by $2-3$ AIS grades was evident when the data were divided by time (Figure 6). A progressively lower proportion of patients improved by 2 3 AIS grades as the time to decompression increased (Fisher's exact test, $p<$ 0.005). The benefit of early decompression appeared to rapidly decrease with time and the relationship between the timing of decompression and the 
proportion of patients improving by 2-3 AIS grades fitted a power curve $\left(r^{2}=\right.$ 0.97, Figure 6).

We also analyzed the proportion of patients improving by 2 or more grades and undergoing closed or open reduction. Four of the 8 patients treated with closed reduction within 12 hours post-injury improved by 2 or more grades (median time to decompression $=5.8$ hours, IQR: $4-10$ ). Only 2 of the fastest 8 patients undergoing open reduction (median time to decompression of 6.2 hours, IQR: $6-6.5$ ) improved by 2 or more grades. However, this difference was not statistically significant. 


\section{DISCUSSION}

This study analyses the process of care for patients with isolated cervical SCI and identifies areas of major delay in the period from the accident scene to surgery. Identifying delays using current data allows the development of strategies to improve the efficiency of patient management. ${ }^{21,22}$ In this study, we found the median time to decompression for cases of isolated cervical SCI within Australia and New Zealand was 21 hours and this improved significantly from 31 hours in 2010 to 19 hours in 2013 . The improvement in surgical timing over the study period was primarily due to a decrease in the time taken to access the operating theatre following arrival at the spinal surgical hospital and, to a lesser extent, an increase in the proportion of patients admitted directly to a surgical centre. Medical stabilisation and radiological investigations did not appear to greatly influence the time to surgery.

We analysed the overall process of care in seven different regions across two countries. A finding common for all services was a significant difference in the timing of decompression when patients were directly admitted to a spinal surgical hospital compared to patients who were admitted to a pre-surgical hospital (12 hours vs. 26 hours respectively). This difference in the timing of surgery was not simply a reflection of the duration of the pre-hospital admission and transfer, as the median time of these components was only 8.9 hours. It may be that the urgency with which investigation and treatment are undertaken is driven to some extent by how rapidly a patient arrives. For example, if a patient arrives in the early morning or many hours following 
injury, investigations and surgery might be deferred until staff and facilities are routinely available.

Eliminating pre-surgical hospital admission would likely shorten the time to decompression. Our data demonstrate that this is gradually occurring in Australia and New Zealand, with the proportion of direct admissions increasing from $34 \%$ of cases in 2010 to $46 \%$ of cases in 2013 . However, it is unlikely that pre-surgical hospital admission can be avoided all together. An important factor driving pre-surgical hospital admission in Australia and New Zealand are the adult major trauma guidelines, which stipulate the triage of patients to the highest level of the trauma service within 45 minutes. An additional factor is the difficulty of excluding other serious injuries in patients with cervical SCls, particularly given the significant hypotension that complicates these injuries. ${ }^{23,24}$

Another key area associated with surgical delay was the time taken to reach the operating theatre following admission to a surgical centre (median time 12.5 hours). The bulk of this time occurred following medical stabilisation, assessment and investigation. Factors limiting access to theatre are unclear, but are likely to revolve around competitive surgical access ${ }^{25}$ in the context of continuing uncertainties regarding the value and optimal timing of decompression. ${ }^{6-10}$

The areas of delay found in this study are in line with those identified by Furlan et al. (2013). ${ }^{21}$ These authors also reported that delay to decompression following cervical SCI was mainly determined by the period in a pre-surgical hospital, and the time waiting for a surgical decision following 
admission to a surgical centre. ${ }^{21}$ Although broadly similar, the delays in the Australasian and Canadian systems differ in several important ways. In the Canadian system, patients generally attended two and sometimes three presurgical hospitals before admission to a spinal surgical hospital. Delays associated with multiple transfers were long, with patients who underwent early decompression ( $<24$ hours, $n=23$ ), spending a median of 9.5 hours at the first pre-surgical hospital alone and over 33 hours if decompression was delayed. In contrast, our data demonstrate that in Australia and New Zealand, patients usually attend only one pre-surgical hospital with a median duration of 8 hours.

\section{Optimal timing of early decompression}

The improvement in the timing of spinal decompression in Australia and New Zealand likely reflects the growing awareness of the value of early surgery. A number of studies and reviews have suggested that early decompression maybe of value in facilitating neurological recovery..$^{6,8-10}$ The largest study in this area (STASCIS), demonstrated a $\geq 2$ AIS grade improvement in $19.8 \%$ of patients with cervical SCI undergoing early decompression (mean 14.2 hours \pm 5.4 ) compared with $8.8 \%$ of patients undergoing late decompression (mean 48.3 hours \pm 29.3$).{ }^{6}$ The results of this study have added to the already favourable view of early decompression amongst surgeons worldwide. ${ }^{26}$

A critical question driving further improvements is the optimal timing of spinal decompression. Pre-clinical studies consistently demonstrate that decompression is best performed as soon as possible following injury. In both small and large animal models attempting to replicate human injury, 
compression of the traumatised cord results in rapid neurological decline, with severe paraplegia developing within 3-8 hours. ${ }^{10,27-33}$ Although spinal surgeons generally believe that operating early is optimal, preferably within 6 hours for patients with severe incomplete injuries, ${ }^{26}$ only Newton et al. (2011) have examined decompression in humans at very early time points. This study evaluated the benefit of closed reduction following low velocity fracturedislocation injuries in rugby players. ${ }^{17}$ Of the 11 patients with complete motor paralysis decompressed within 4 hours, 8 made a complete recovery. None of the patients decompressed after this time made a complete recovery, while only 3 out of $30(10 \%)$ recovered to grade AIS grade D. While encouraging, uncertainty remains and perhaps it is not possible to fully resolve the efficacy of early decompression and surgical stabilisation without a clinical trial. No other study has examined decompression within the optimal time frame suggested by the pre-clinical literature, although Papadololous et al. (2002) found that outcomes following decompressive surgery were inversely proportional to the time to decompression. ${ }^{7}$

The data from the present study support the argument that decompression should be performed as early as possible. Although retrospective and based on small patient numbers, our data suggest that the proportion of patients likely to benefit from early surgery rapidly declines with time. Based on Newton and colleagues $(2011)^{17}$ data, the optimal time for early decompression may be within the first 4 hours following injury. Closed reduction, performed in a median time of 6 hours in this study, appears to be the method most likely to achieve rapid realignment of the vertebral column within this time frame. The proportion of patients that might benefit from 
decompression within 4 hours is unclear, although more than half appeared to benefit in Newton and colleagues (2011) study. ${ }^{17}$ It is likely that patients with adverse factors such as bleeding into the cord, a long lesion length ${ }^{34}$ or a high initial force of injury would improve less. Because of the apparent small effect size of decompression beyond 4 hours, adequately powered studies would need to be large to detect differences between groups undergoing surgery before and after 24 hours. We could not detect a clear relationship between the timing of early decompression and improvement in AIS grade in our study population when analysed in this way.

\section{Minimising the time to decompression}

The data from this study suggest a number of approaches that may facilitate early decompression in patients with cervical SCl:

1. Direct admission to a surgical centre.

2. Decreased pre-surgical hospital admission time.

3. Rapid access to the operating theatre following medical stabilisation and investigation.

Several measures have the potential to help achieve these changes. Firstly, it is important that paramedics are able to confidently identify cases of isolated $\mathrm{SCl}$. This may help the decision on hospital destination and enable early notification of the spinal team involved at surgical centres. Early notification may enable medical staff involved in the care of spinal patients to organize radiological investigations and access to the operating theatre. Prioritising treatment and theatre access using a "Code Spine" would perhaps be optimal. 
Systems that identify and give priority to certain groups of patients as well as dedicated emergency theatres have been shown to reduce pre-operative delays and improve theatre efficiency. ${ }^{35}$ Avoiding pre-surgical hospital admission would be optimal, however as discussed, in many cases this is unavoidable. Reducing the duration of the pre-surgical hospital admission would seem logical in these cases. This might be facilitated by increased awareness of the urgency of early surgery, pre-hospital spinal management guidelines as well as paramedic pre-notification of the spinal surgical centre to help guide management and transfer.

\section{Study limitations}

In this study, analysis of the process of care was limited to patients with isolated cervical SCl within Australia and New Zealand. Exclusion criteria were carefully chosen so as to give the clearest picture of the areas in which delays occurred. Patients with multi-trauma were excluded, as spinal surgery may be delayed while other life threatening injuries are managed. Patients with TCCS were also excluded because of the current lack of consensus on the timing of surgery. Similarly, patients older than 70 were excluded because of the frequent occurrence of TCCS in this population and the potential for comorbidities delaying surgery. We also excluded patients with high cervical spinal cord injury (C0-C2), as the surgical management of these patients is often complicated. Analysis of the relationship of the timing of surgery to outcome was limited to AIS grade, as data on other outcomes including ASIA motor and sensory scores, was not collected as part of this study. 


\section{CONCLUSION}

The median time to decompression in cases of isolated cervical $\mathrm{SCl}$ across Australia and New Zealand improved significantly over the study period. The fastest times to decompression occurred with closed reduction. Time to decompression appeared to be an important factor related to outcome, with a rapid reduction in the proportion of cases demonstrating substantial (2 to 3 AIS grade) recovery as time to decompression increased. Across Australia and New Zealand the timing of decompression surgery was principally determined by two factors: admission to a pre-surgical hospital and the time taken to access the operating theatre. Direct admission to a spinal surgical hospital, rapid access to the operating theatre and, where indicated closed reduction of cervical $\mathrm{SCl}$, are likely to be the most effective strategies to reduce the time to decompression.

\section{ACKNOWLEDGMENTS}

This study is supported by the National Health and Medical Research Council; Institution for Safety, Compensation and Recovery Research; Spinal Cord Injury Network and Neurotrauma Research Program.

\section{AUTHOR DISCLOSURE STATEMENT}

No competing financial interests exist. 


\section{REFERENCES}

1. Devivo, M.J. (2012). Epidemiology of traumatic spinal cord injury: trends and future implications. Spinal Cord 50, 365-372.

2. Norton, L. (2010). Spinal cord injury, Australia 2007-08. AlHW cat no. INJCAT 128. Injury Research and Statistics Series Australian Institute of Health and Welfare.

3. Ramer, L.M., Ramer, M.S., and Bradbury, E.J. (2014). Restoring function after spinal cord injury: towards clinical translation of experimental strategies. Lancet Neurol. 13, 1241-1256.

4. Wilson, J.R., Forgione, N., and Fehlings, M.G. (2013). Emerging therapies for acute traumatic spinal cord injury. CMAJ 185, 485-492.

5. Batchelor, P.E., Skeers, P., Antonic, A., Wills, T.E., Howells, D.W., Macleod, M.R., and Sena, E.S. (2013). Systematic review and metaanalysis of therapeutic hypothermia in animal models of spinal cord injury. Plos One 8, e71317.

6. Fehlings, M.G., Vaccaro, A., Wilson, J.R., Singh, A., W Cadotte, D., Harrop, J.S., Aarabi, B., Shaffrey, C., Dvorak, M., Fisher, C., Arnold, P., Massicotte, E.M., Lewis, S., and Rampersaud, R. (2012). Early versus delayed decompression for traumatic cervical spinal cord injury: results of the Surgical Timing in Acute Spinal Cord Injury Study (STASCIS). PloS one 7, e32037.

7. Papadopoulos, S.M., Selden, N.R., Quint, D.J., Patel, N., Gillespie, B., and Grube, S. (2002). Immediate spinal cord decompression for cervical spinal cord injury: feasibility and outcome. J. Trauma 52, 323332. 
8. Furlan, J.C., Noonan, V., Cadotte, D.W., and Fehlings, M.G. (2011). Timing of decompressive surgery of spinal cord after traumatic spinal cord injury: an evidence-based examination of pre-clinical and clinical studies. J. Neurotrauma 28, 1371-1399.

9. Wilson, J.R., Singh, A., Craven, C., Verrier, M.C., Drew, B., Ahn, H., Ford, M., and Fehlings, M.G. (2012). Early versus late surgery for traumatic spinal cord injury: the results of a prospective Canadian cohort study. Spinal cord 50, 840-843.

10. Dvorak, M.F., Noonan, V.K., Fallah, N., Fisher, C.G., Finkelstein, J., Kwon, B.K., Rivers, C.S., Ahn, H., Paquet, J., Tsai, E.C., Townson, A., Attabib, N., Bailey, C.S., Christie, S.D., Drew, B., Fourney, D.R., Fox, R., Hurlbert, R.J., Johnson, M.G., Linassi, A.G., Parent, S., and Fehlings, M.G. (2015). The influence of time from injury to surgery on motor recovery and length of hospital stay in acute traumatic spinal cord injury: an observational canadian cohort study. J Neurotrauma 32, 645-654.

11. Croce, M.A., Bee, T.K., Pritchard, E., Miller, P.R., and Fabian, T.C. (2001). Does optimal timing for spine fracture fixation exist? Ann. Surg. $233,851-858$.

12. Kerwin, A.J., Frykberg, E.R., Schinco, M.A., Griffen, M.M., Murphy, T., and Tepas, J.J. (2005). The effect of early spine fixation on nonneurologic outcome. J. Trauma 58, 15-21.

13. McKinley, W., Meade, M.A., Kirshblum, S., and Barnard, B. (2004). Outcomes of early surgical management versus late or no surgical 
intervention after acute spinal cord injury. Arch. Phys. Med Rehabil. 85, 1818-1825.

14. Sapkas, G.S., and Papadakis, S.A. (2007). Neurological outcome following early versus delayed lower cervical spine surgery. J. Orthop. Surg. (Hong Kong) 15, 183-186.

15. Schinkel, C., Frangen, T.M., Kmetic, A., Andress, H.J., Muhr, G., and German Trauma, R. (2006). Timing of thoracic spine stabilization in trauma patients: impact on clinical course and outcome. J. Trauma 61, 156-160.

16. Vaccaro, A.R., Daugherty, R.J., Sheehan, T.P., Dante, S.J., Cotler, J.M., Balderston, R.A., Herbison, G.J., and Northrup, B.E. (1997). Neurologic outcome of early versus late surgery for cervical spinal cord injury. Spine 22, 2609-2613.

17. Newton, D., England, M., Doll, H., and Gardner, B.P. (2011). The case for early treatment of dislocations of the cervical spine with cord involvement sustained playing rugby. J. Bone Joint Sur. Br. 93, 16461652.

18. Bourassa-Moreau, E., Mac-Thiong, J.M., Feldman, D.E., Thompson, C., and Parent, S. (2013). Non-neurological outcomes after complete traumatic spinal cord injury: the impact of surgical timing. J. Neurotrauma 30, 1596-1601.

19. van Middendorp, J.J., Hosman, A.J.F., Donders, A.R.T., Pouw, M.H., Ditunno, J.F., Jr., Curt, A., Geurts, A.C.H., Van de Meent, H., and EmSCI Study Group. (2011). A clinical prediction rule for ambulation 
outcomes after traumatic spinal cord injury: a longitudinal cohort study. Lancet 377, 1004-1010.

20. Harris, P.A., Taylor, R., Thielke, R., Payne, J., Gonzalez, N., and Conde, J.G. (2009). Research electronic data capture (REDCap): a metadata-driven methodology and workflow process for providing translational research informatics support. J. Biomed Inform. 42, 377381.

21. Furlan, J.C., Tung, K., and Fehlings, M.G. (2013). Process benchmarking appraisal of surgical decompression of spinal cord following traumatic cervical spinal cord injury: opportunities to reduce delays in surgical management. J. Neurotrauma 30, 487-491.

22. Senn, G.F. (2000). Benchmarking: your performance measurement and improvement tool. Gastroenterol. Nurs. 23, 221-225.

23. Kong, C.Y., Hosseini, A.M., Belanger, L.M., Ronco, J.J., Paquette, S.J., Boyd, M.C., Dea, N., Street, J., Fisher, C.G., Dvorak, M.F., and Kwon, B.K. (2013). A prospective evaluation of hemodynamic management in acute spinal cord injury patients. Spinal Cord 51, 466-471.

24. Vale, F.L., Burns, J., Jackson, A.B., and Hadley, M.N. (1997). Combined medical and surgical treatment after acute spinal cord injury: results of a prospective pilot study to assess the merits of aggressive medical resuscitation and blood pressure management. J. Neurosur. $87,239-246$.

25. O'Leary, D.P., Beecher, S., and McLaughlin, R. (2014). Emergency surgery pre-operative delays - realities and economic impacts. Int. J. Sur. $12,1333-1336$. 
26. Fehlings, M.G., Rabin, D., Sears, W., Cadotte, D.W., and Aarabi, B. (2010). Current practice in the timing of surgical intervention in spinal cord injury. Spine 35, S166-173.

27. Batchelor, P.E., Kerr, N.F., Gatt, A.M., Aleksoska, E., Cox, S.F., Ghasem-Zadeh, A., Wills, T.E., and Howells, D.W. (2010). Hypothermia prior to decompression: buying time for treatment of acute spinal cord injury. J Neurotrauma 27, 1357-1368.

28. Batchelor, P.E., Wills, T.E., Skeers, P., Battistuzzo, C.R., Macleod, M.R., Howells, D.W., and Sena, E.S. (2013). Meta-analysis of preclinical studies of early decompression in acute spinal cord injury: a battle of time and pressure. Plos One 8, e72659.

29. Dimar, J.R., 2nd, Glassman, S.D., Raque, G.H., Zhang, Y.P., and Shields, C.B. (1999). The influence of spinal canal narrowing and timing of decompression on neurologic recovery after spinal cord contusion in a rat model. Spine 24, 1623-1633.

30. Shields, C.B., Zhang, Y.P., Shields, L.B.E., Han, Y., Burke, D.A., and Mayer, N.W. (2005). The therapeutic window for spinal cord decompression in a rat spinal cord injury model. Journal of neurosurgery. Spine 3, 302-307.

31. Carlson, G.D., Gorden, C.D., Oliff, H.S., Pillai, J.J., and LaManna, J.C. (2003). Sustained spinal cord compression: part I: time-dependent effect on long-term pathophysiology. J. Bone Joint Sur. Am. 85-A, 8694. 
32. Delamarter, R.B., Sherman, J., and Carr, J.B. (1995). Pathophysiology of spinal cord injury. Recovery after immediate and delayed decompression. J. Bone Joint Sur. Am. 77, 1042-1049.

33. Rabinowitz, R.S., Eck, J.C., Harper, C.M., Jr., Larson, D.R., Jimenez, M.A., Parisi, J.E., Friedman, J.A., Yaszemski, M.J., and Currier, B.L. (2008). Urgent surgical decompression compared to methylprednisolone for the treatment of acute spinal cord injury: a randomized prospective study in beagle dogs. Spine 33, 2260-2268.

34. Miyanji, F., Furlan, J.C., Aarabi, B., Arnold, P.M. and Fehlings, M.G. (2007). Acute cervical traumatic spinal cord injury: MR Imaging findings correlated with neurologic outcome - Prospective study with 100 consecutive patients. Radiology 243, 820-827.

35. Leppaniemi, A.. and Jousela, I. (2014). A traffic-light coding system to organize emergency surgery across surgical disciplines. Br. J. Sur. $101, \mathrm{e} 134-140$ 


\begin{tabular}{|c|c|c|}
\hline \multirow{2}{*}{ Table } & Characteristics & n (\%) \\
\hline & Age $($ mean $\pm S D)$ & $36 \pm 17$ \\
\hline & Male & $160(83)$ \\
\hline & \multicolumn{2}{|l|}{ Accident category } \\
\hline & Motor vehicle occupants (speed $>60 \mathrm{~km} / \mathrm{hr}$ ) & $37(19)$ \\
\hline & High fall ( $\geq 1$ metre) & $31(16)$ \\
\hline & Water related & $31(16)$ \\
\hline & Struck by or collision with person or object & $27(14)$ \\
\hline & Unprotected road user & $19(10)$ \\
\hline & Motor vehicle occupants (speed unknown) & $15(8)$ \\
\hline & Low fall (same level or height < 1 metre) & $15(8)$ \\
\hline & Others & $9(5)$ \\
\hline & Motor vehicle occupants (speed $\geq 60 \mathrm{~km} / \mathrm{hr}$ ) & $8(4)$ \\
\hline & \multicolumn{2}{|l|}{ Location of accident } \\
\hline & Metropolitan & $108(56)$ \\
\hline & Rural & $62(32)$ \\
\hline & Remote & $20(10)$ \\
\hline & Unknown & $2(1)$ \\
\hline & \multicolumn{2}{|l|}{ AIS grade on acute admission } \\
\hline & AIS A & $88(46)$ \\
\hline & AIS B & $32(17)$ \\
\hline & AIS C & $28(14)$ \\
\hline & AIS D & $20(10)$ \\
\hline & Unknown & $24(13)$ \\
\hline & \multicolumn{2}{|l|}{ AIS grade at rehabilitation discharge } \\
\hline & AIS A & $67(35)$ \\
\hline & AIS B & $31(16)$ \\
\hline & AIS C & $14(7)$ \\
\hline & AIS D & $69(36)$ \\
\hline & Unknown & $11(6)$ \\
\hline
\end{tabular}

\section{Demographics and Injury Characteristics}

SD, standard deviation; AIS, American Spinal Injury Association (ASIA) Impairment Scale. 
Figure 1. Distribution of level of injury

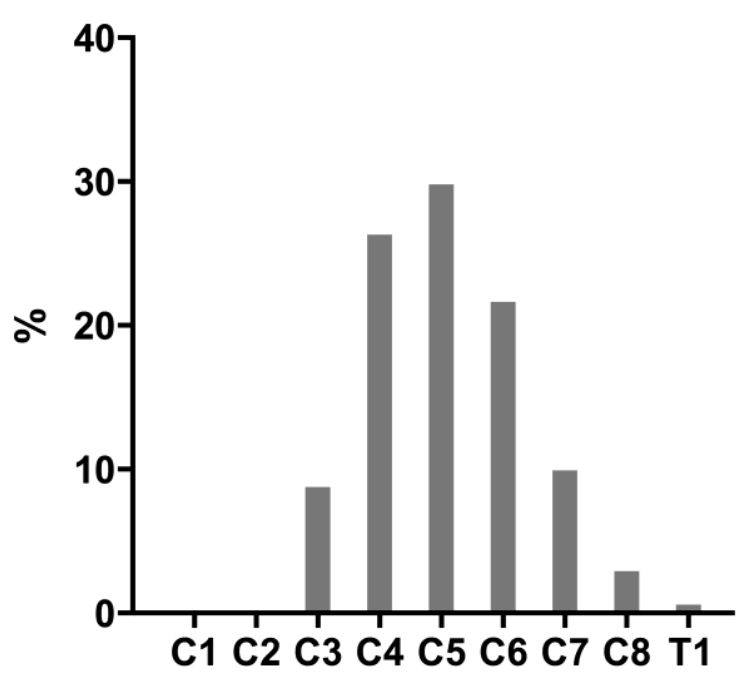

Figure 1. Distribution of level of injury

Histogram showing the proportion of patients included at each neurological level of injury. 
Figure 2. Timing of Spinal Decompression

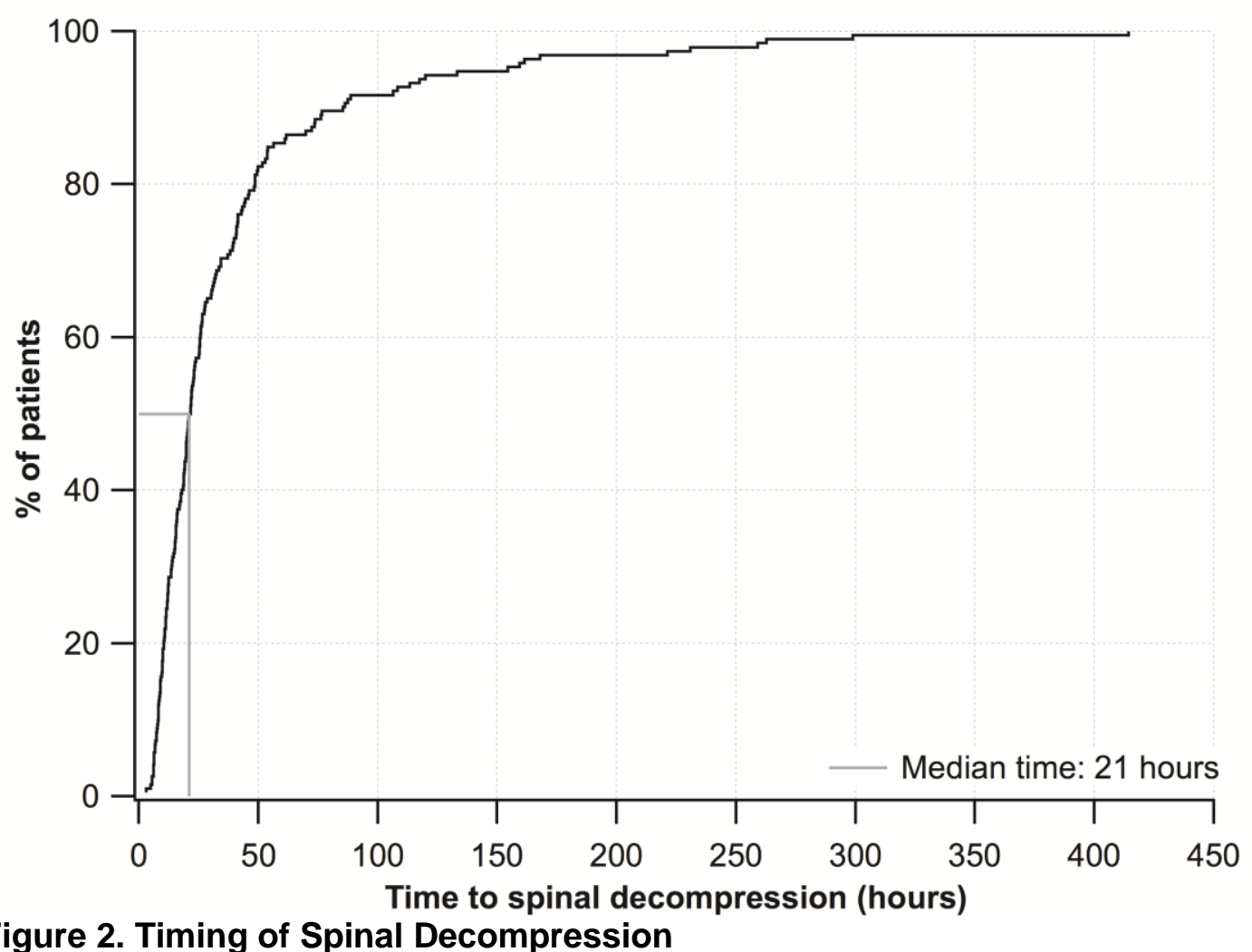

Figure 2. Timing of Spinal Decompression

Cumulative histogram showing the proportion of patients decompressed at different times (black line). The median time of spinal decompression is indicated by the vertical grey line. 
Figure 3. Time to Spinal Decompression by year
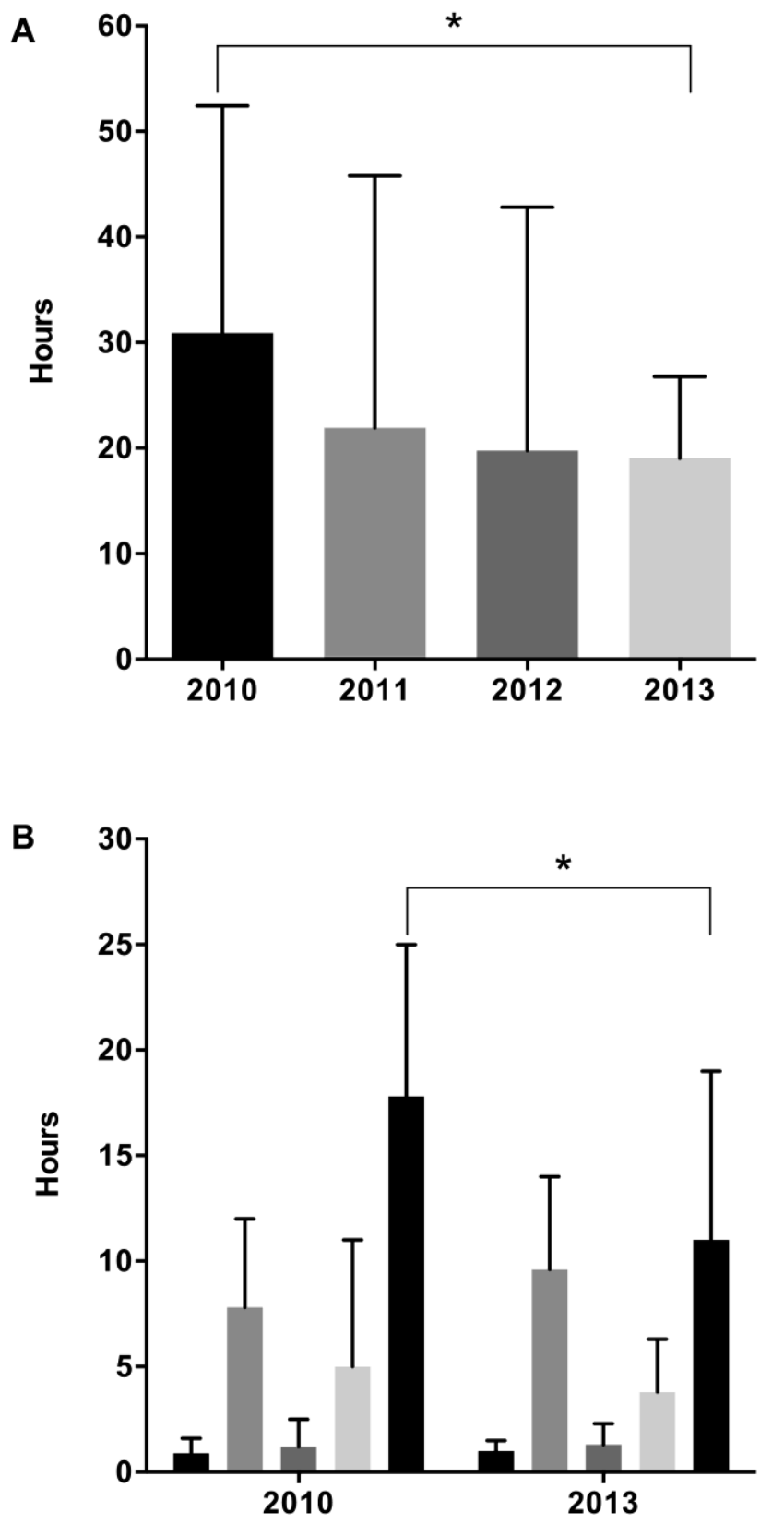

- Paramedic time

- Pre-surgical hospital admission

- Spinal CT

Spinal MRI

- Surgical hospital admission

Figure 3. Time to Spinal Decompression by year

(A) Bar chart showing the median time (IQR) to decompression for each year of the study. ${ }^{*} p=0.008$. (B) Changes in the process of care by year. Bar chart showing the median time (IQR) of the main phases between accident and spinal decompression. Surgical hospital admission was the only phase that significantly changed between 2010 and 2013. * $p=0.02$ ). 


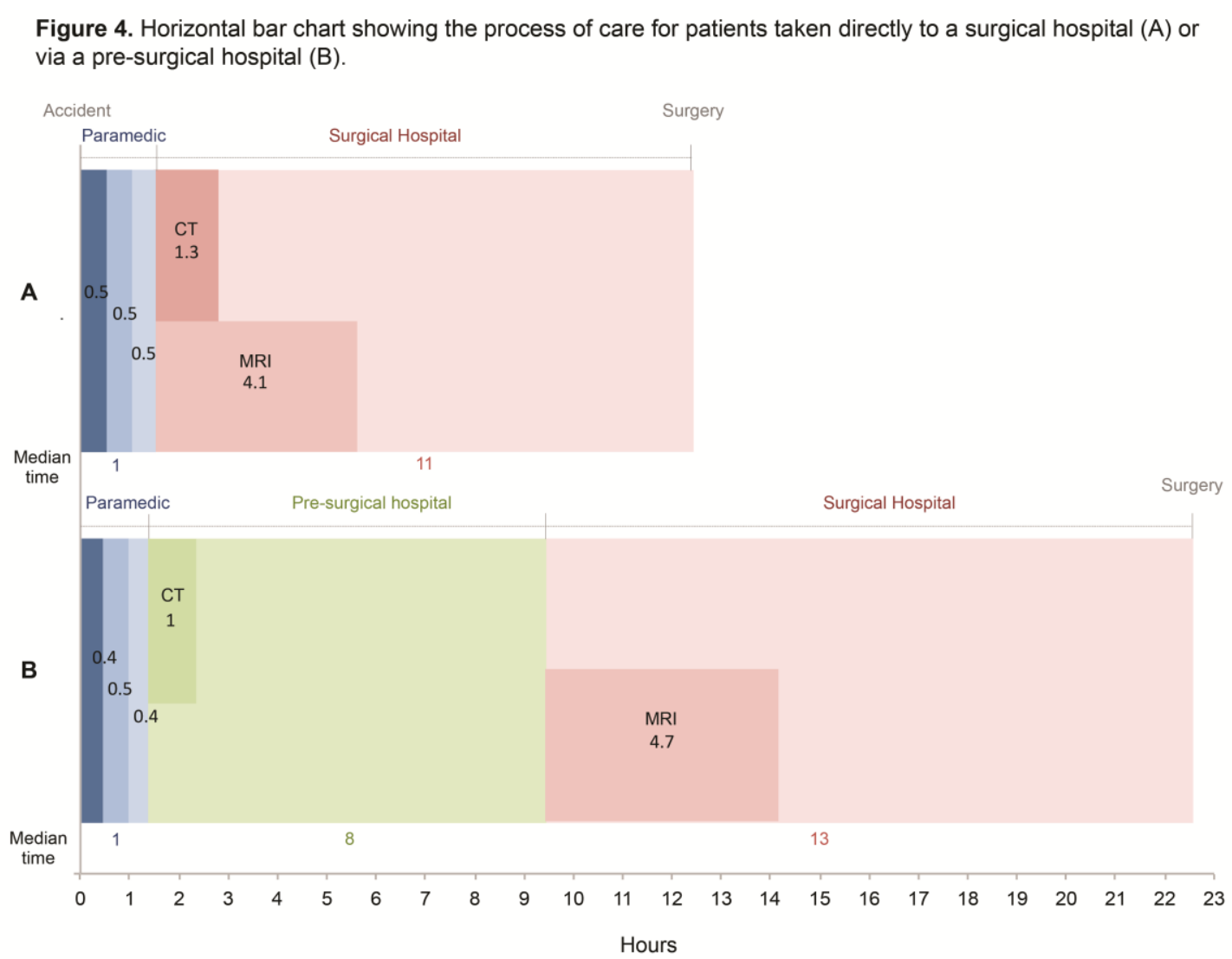

Figure 4. Horizontal bar chart showing the process of care for patients taken directly to a surgical hospital (A) or via pre-surgical hospital (B).

The median time of each phase is shown for both groups of patients in different colours. Each stage of paramedic involvement is shown in different shades of blue (dark blue $=$ accident to ambulance arrival, blue $=$ ambulance arrival to ambulance departure and light blue = ambulance departure to hospital arrival). The pre-surgical hospital phase is shown in light green and the surgical hospital admission is shown in light pink. The time taken to complete radiological investigations is shown as a darker shade in the respective phase. The overall median time to spinal decompression of cases taken directly to a surgical hospital (12 hours, $n=78$ ) was significantly shorter than cases taken via a pre-surgical hospital (26 hours, $n=114, p<0.0001$ ). Please note summation of the median times for each segment does not yield the overall median times to spinal decompression for each group. 
Figure 5. Factors associated with early and delayed spinal decompression
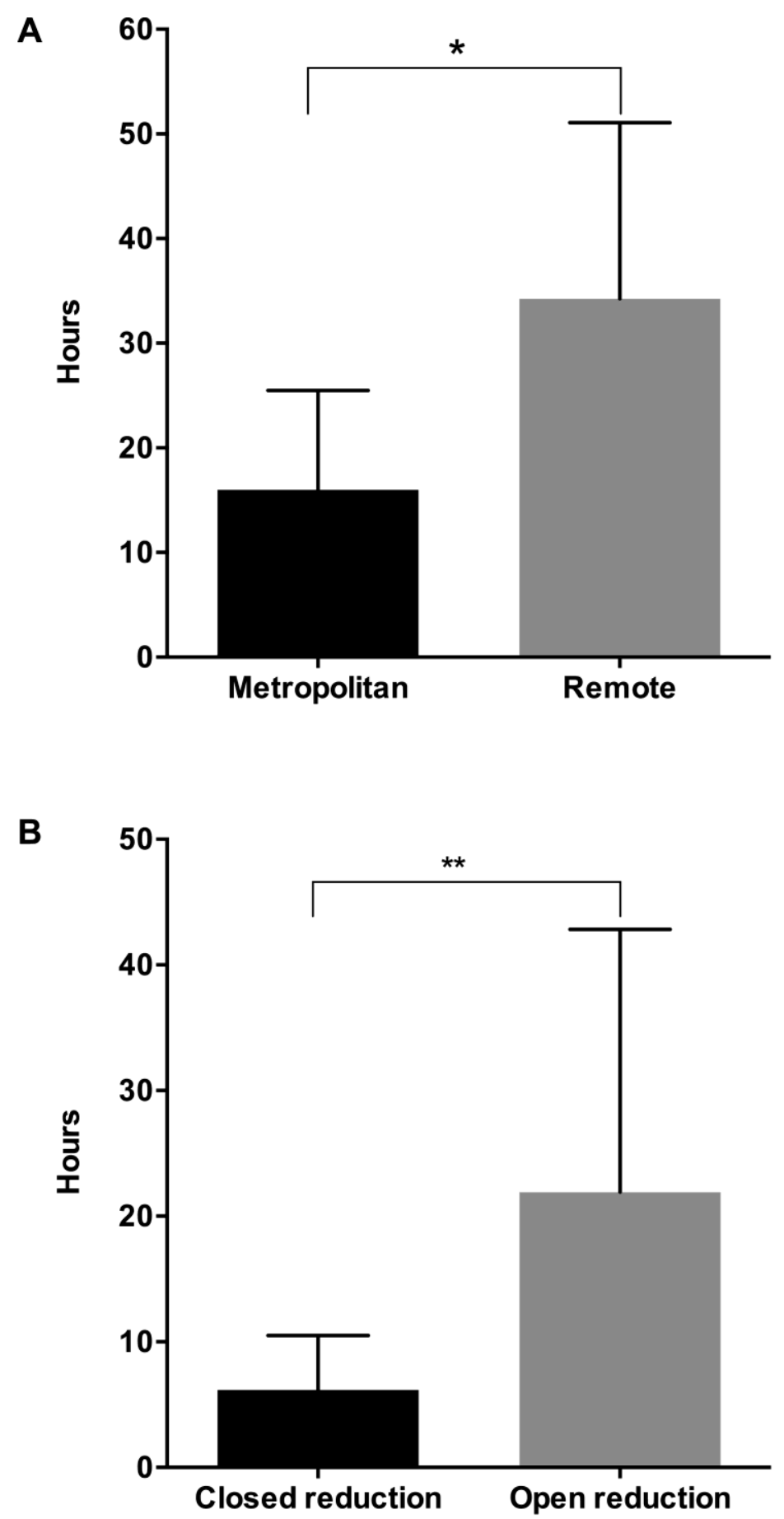

Figure 5. Factors associated with early and delayed spinal decompression. 
(A) Median time (IQR) of spinal decompression for cases injured in a metropolitan area vs. cases injured in a remote area, ${ }^{*} p=0.0002$. (B) Median time (IQR) of closed reduction vs. open reduction, ${ }^{* \star} p<0.0001$. 
Figure 6. Timing of spinal decompression and neurological change.

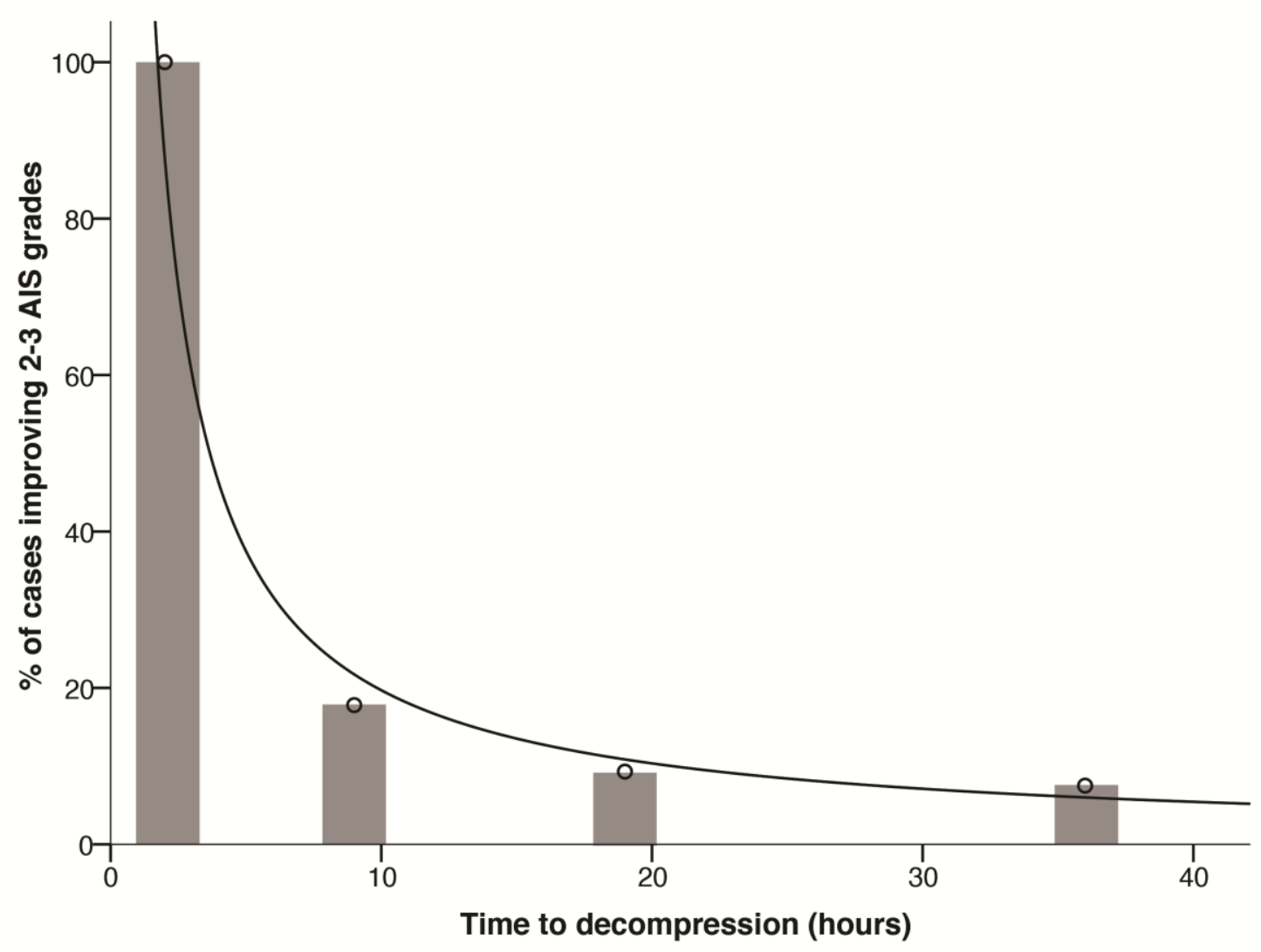

Figure 6. Timing of spinal decompression and neurological change.

Bar graph showing the proportion of patients improving by 2-3 AIS grades vs time to decompression. A significantly lower proportion of patients improved by 2-3 AIS grades as the time to decompression increased (Fisher's exact test, $p<0.005$ ). Number of patients improving by 2-3 AIS grade in each group: 0-4 = 2/2, 4-14 = 8/45, $14-24=4 / 43$ and $24-48=3 / 40$. The proportion of patients improving by $2-3$ AIS grades rapidly decreased with time. The regression curve obeyed a power-law distribution $\left(r^{2}=0.97\right)$. 
Supplement 1. Figure A and B
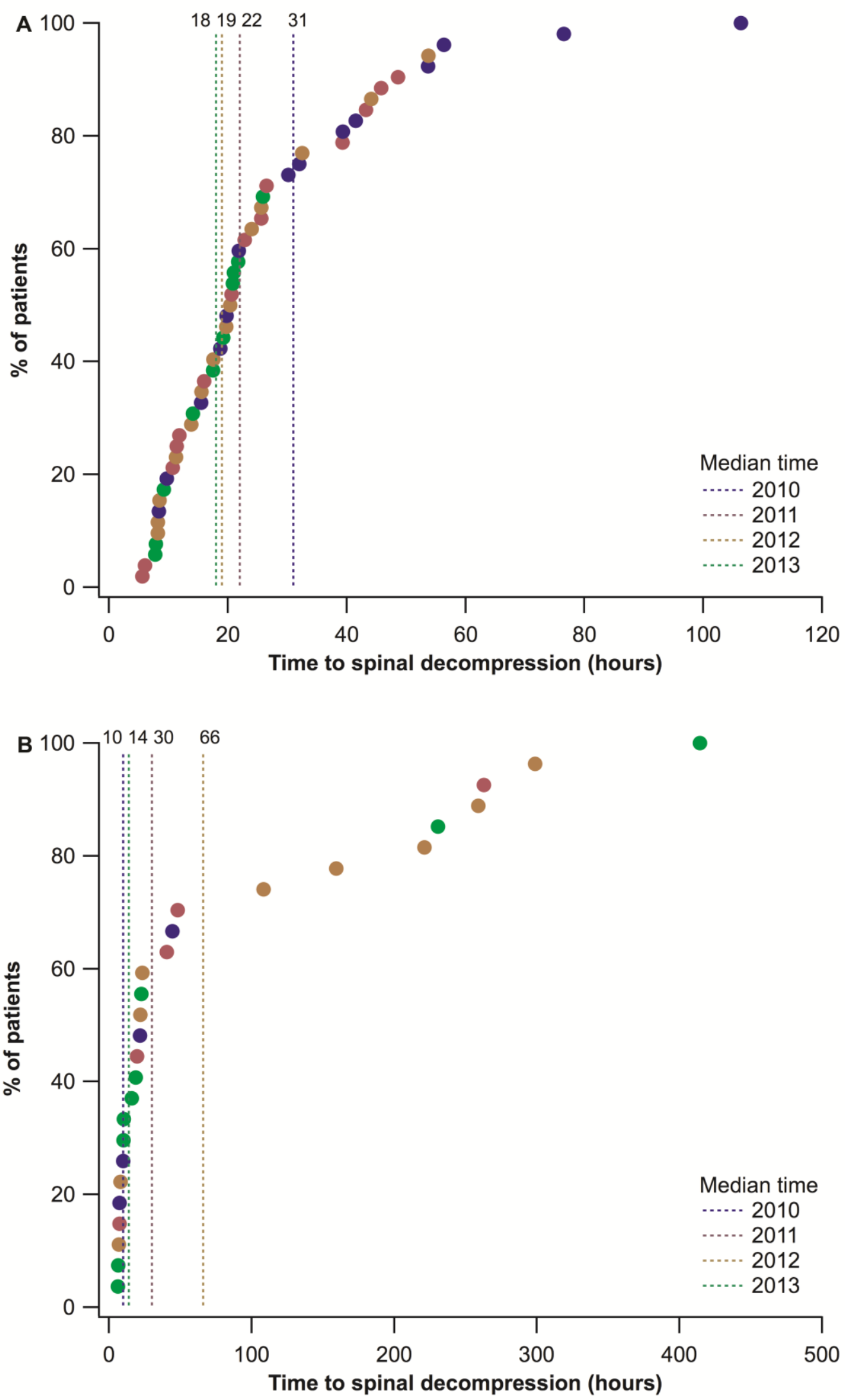
Supplement 1. Figure C and D
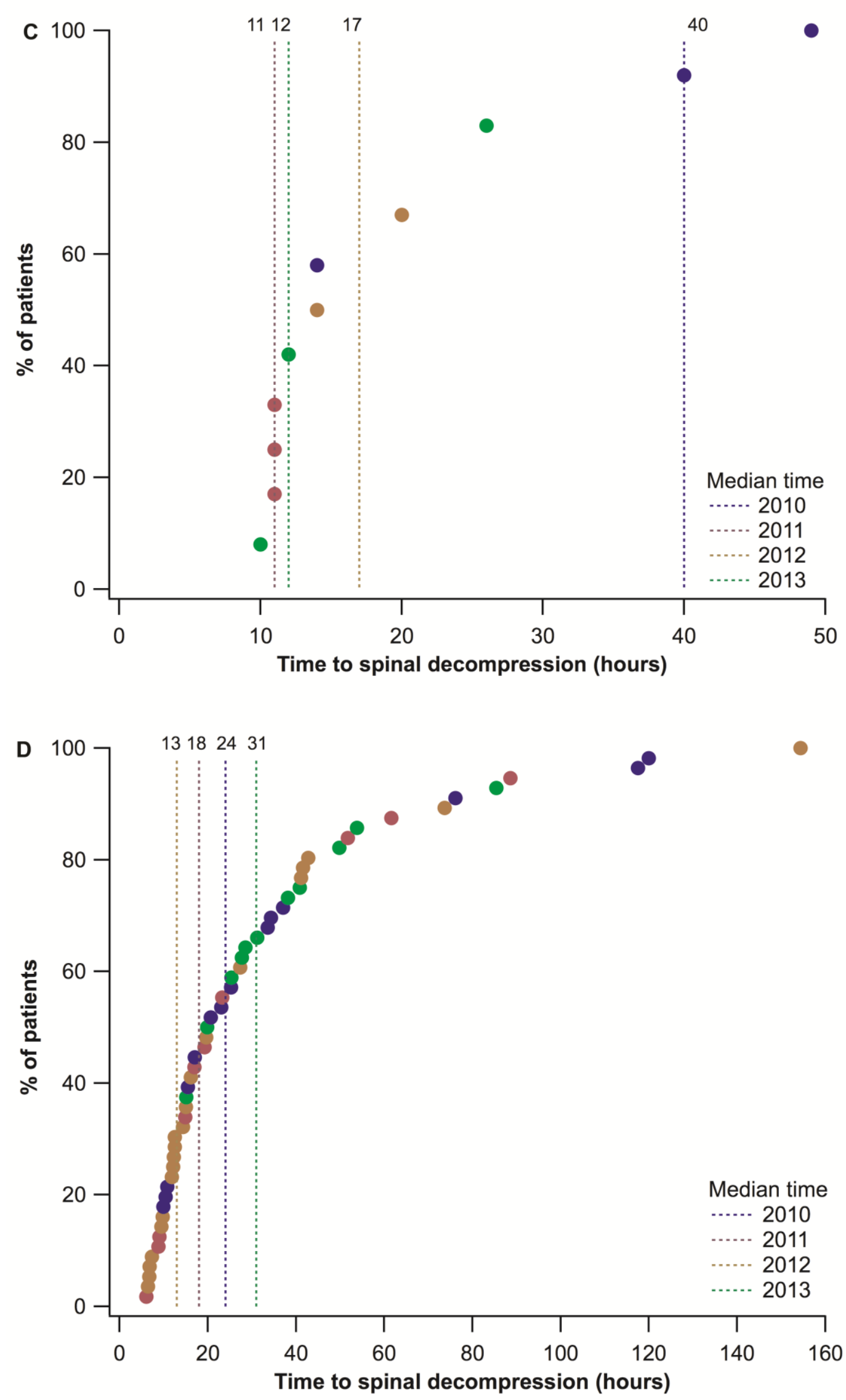
Supplement 1. Figure E

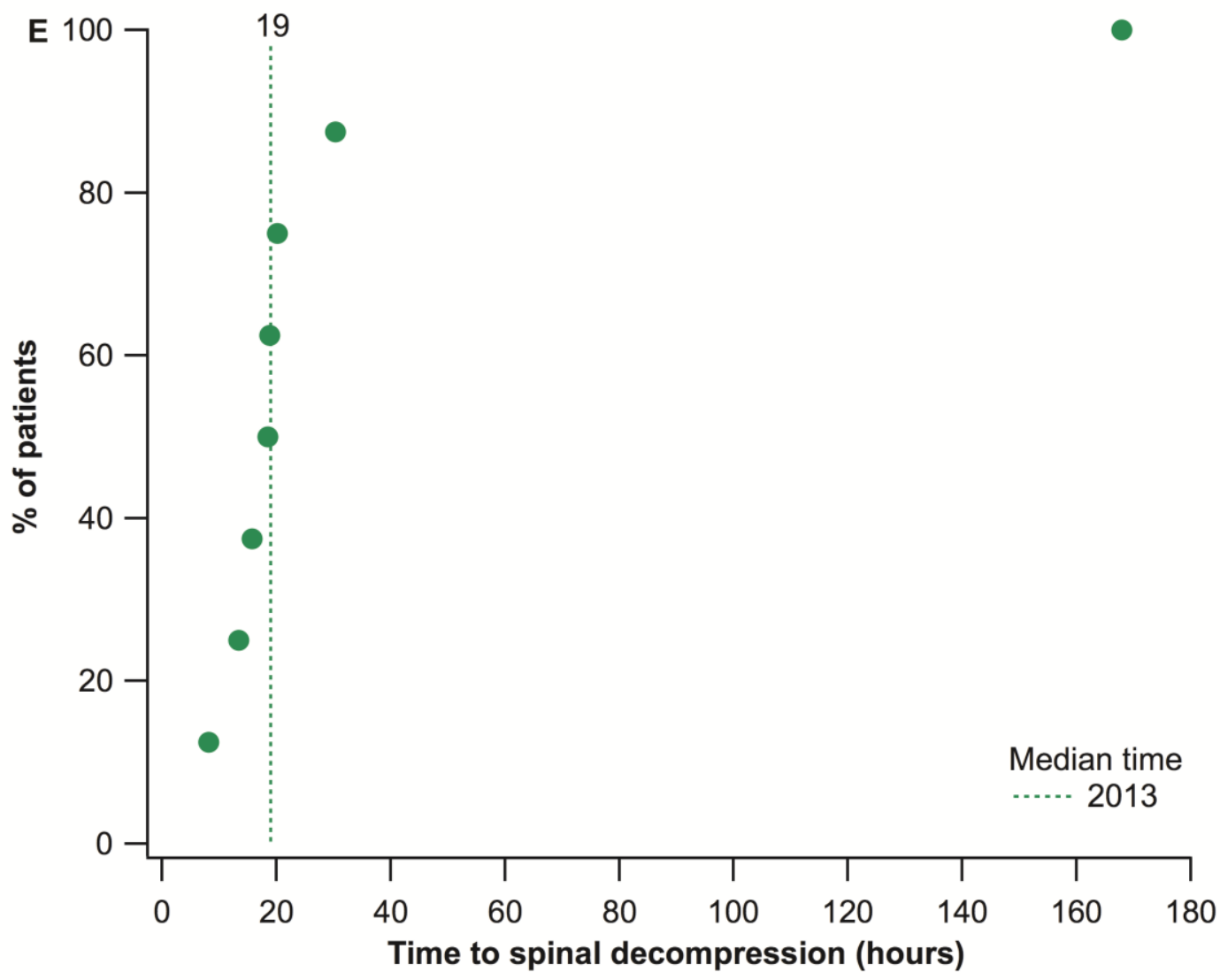


Supplement 1. Figure F and G
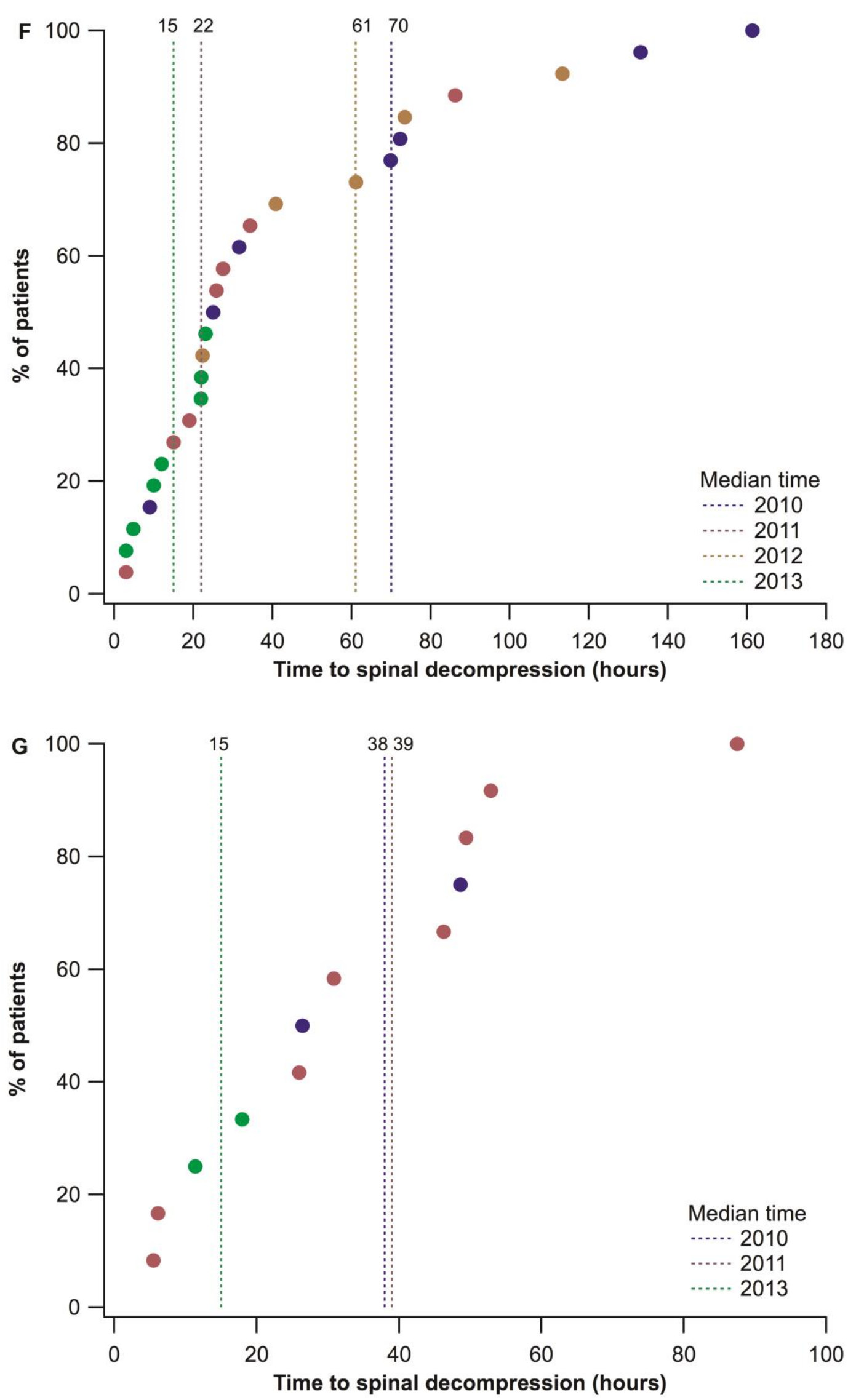


\section{Supplement 1. Timing of spinal decompression by site.}

Graph showing the cumulative proportion of patients decompressed at different times in (A) VIC (Victoria) and (B) WA (Western Australia). The different colours indicate the year the patient was decompressed. The vertical dashed lines give the median time of spinal decompression for each year. Blue $=2010$, Purple $=2011$, Brown $=$ 2012 and Green = 2013.

Graph showing the cumulative proportion of patients decompressed at different times in (C) SA (South Australia) and (D) QLD (Queensland). The different colours indicate the year the patient was decompressed. The vertical dashed lines give the median time of spinal decompression for each year. Blue $=2010$, Purple $=2011$, Brown $=$ 2012 and Green = 2013.

Graph showing the cumulative proportion of patients decompressed at different times in (E) NSW (New South Wales) over six months in 2013. The vertical dashed line gives the median time of spinal decompression.

Graph showing the cumulative proportion of patients decompressed at different times in (F) Christchurch and (G) Auckland. The different colours indicate the year the patient was decompressed. The vertical dashed lines give the median time of spinal decompression for each year. Blue $=2010$, Purple $=2011$, Brown $=2012$ and Green $=2013$. 